\title{
Epidemiology and Treatment Outcomes of Head Injury in Bangladesh: Perspective from the Largest Tertiary Care Hospital
}

\author{
Sukriti Das ${ }^{1}$ Bipin Chaurasia ${ }^{2}$ Dipankar Ghosh ${ }^{1}$ Asit Chandra Sarker ${ }^{1}$ \\ ${ }^{1}$ Department of Neurosurgery, Dhaka Medical College and Hospital, \\ Dhaka, Bangladesh \\ 2 Department of Neurosurgery, Neurosurgery Clinic, Birgunj, Nepal, \\ Address for correspondence Sukriti Das, FCPS, MS, FRCS, \\ Department of Neurosurgery, Dhaka Medical College and Hospital, \\ Dhaka 1000, Bangladesh (e-mail: sukriti66@yahoo.com).
}

Indian J Neurotrauma 2023;20:11-17.

\begin{abstract}
Background Traumatic brain injury (TBI) is one of the leading causes of mortality and morbidity. Economic impact is much worse in developing countries like Bangladesh, as victims are frequently male, productive, and breadwinners of the families.

Objectives The objective of our study was to highlight the etiological pattern and distribution of varieties of head injuries in Bangladesh and give recommendations regarding how this problem can be solved or reduce to some extent at least.

Methods From January 2017 to December 2019, a total of 14,552 patients presenting with head injury at emergency got admitted in Neurosurgery department of Dhaka Medical College and Hospital and were included in this study.

Results The most common age group was 21 to 30 years $(36 \%: 5,239)$ with a male-tofemale ratio of 2.6:1. Injury was mostly caused by road traffic accident (RTA [58.3\%: 8,484]), followed by fall $(25 \%: 3,638)$ and history of assault $(15.3 \%: 2,226)$. The common varieties of

Keywords

- traumatic brain injury

- RTA

- ASDH

- AEDH

- GOS

- contusion

- DC head injury were: acute extradural hematoma (AEDH [42.30\%: 1,987]), skull fracture either linear or depressed (28.86\%: 1,347), acute subdural hematoma (ASDH [12.30\%: 574]), brain contusion (10.2\%: 476), and others (6.04\%: 282).

Conclusion RTA is the commonest cause of TBI, and among them motor bike accident is the severe most form of TBI. AEDH is the commonest variety of head injuries. Proper steps taken by the Government, vehicle owners, and drivers, and proper referral system and prompt management in the hospital can reduce the mortality and morbidity from TBI in Bangladesh.
\end{abstract}

\section{Introduction}

Neurosurgery department is the super specialized department in Dhaka Medical College and Hospital (DMCH) that has to face a huge number of neuro trauma patients every day. Neurotrauma is one of the leading causes of death in Bangladesh; the World Health Organization (WHO) estimated that it kills over 21,000 lives in the country

article published online February 23, 2021
DOI https://doi.org/ $10.1055 / \mathrm{s}-0040-1718780$. ISSN 0973-0508. annually. ${ }^{1}$ Over five million people die due to head injury around the world each year despite no longer being perceived as unavoidable but largely preventable events. ${ }^{2}$ Out of these huge number, 1.2 million cases are due to road traffic accident (RTA), $90 \%$ of which take place in low- and middle-income countries. ${ }^{3,4}$ It is predicted that by 2020 , RTA will become a major culprit in the total disease burden. ${ }^{2,3}$ In India, there is an accident every minute and death every 8 minutes and

(c) 2021. The Author(s).

This is an open access article published by Thieme under the terms of the Creative Commons Attribution License, permitting unrestricted use, distribution, and reproduction so long as the original work is properly cited. (https://creativecommons.org/licenses/by/4.0/)

Thieme Medical and Scientific Publishers Pvt. Ltd., A-12, 2nd Floor, Sector 2, Noida-201301 UP, India 
significant variations also arise between different states of India. ${ }^{5-7}$ Among the injuries that occur due to traumatic brain injury (TBI), the recorded deaths number $>50,000$ yearly in the United States. ${ }^{8}$ Each year $\sim 370,000$ new cases of TBI are hospitalized in the United States ${ }^{9}$ and the figure is $>100,000$ for Europe. ${ }^{10}$ Young people are the most common sufferers of TBI, resulting in long-term disabilities that, in addition to the personal toll, affect both the work force and economy. ${ }^{11}$ Expenditure on TBI-related costs in the United States alone is estimated to be $\$ 17$ billion per year. ${ }^{12}$

TBI is defined as an alteration in brain function, or other evidence of changed brain pathology, caused by an external force to the brain. ${ }^{13}$ Alteration in brain function generally means any period of loss or a decreased level of consciousness. However, not all blows or jolts to the head result in TBI. ${ }^{14} \mathrm{TBI}$ is one of the most common forms of severe injury with a high death toll or life-long disabilities seen among patients. It is estimated to cause an annual loss of $\$ 30$ billion in developed countries. ${ }^{15}$ It is also estimated that $>1.7$ million head injuries are encountered in the United States alone. $^{15}$ The incidence of TBI has been contained as $>600 / 100,000$ cases by the WHO, ${ }^{16}$ leading to $\sim 90 / 100,000$ admission in the hospital. ${ }^{17}$

TBI is a traumatic acquired insult to the brain resulting from an external mechanical force. ${ }^{18}$ This may be accompanied by loss or alteration in sensorium. It remains one of the leading causes of morbidity, mortality, and economic loss worldwide. TBI is the commonest cause of mortality below 45 years of age. Such an impact is much worse in developing countries where per capita income is low and dependence ratio is high. Moreover, illiteracy, poverty, and negligence frequently delay the acquisition of medical attention, which exacerbates the curse and complications.

We are very sorry to say that unfortunately the epidemiological data of TBI in our region are scarce. The objective of this study is to highlight the pattern and distribution of TBI to enhance trace research, improve treatment strategies, and update and rectify the Government policy to reduce RTA mortality and morbidity.

\section{Materials and Methods}

The prospective study was conducted in the department of Neurosurgery, DMCH, from January 2017 to December 2019. A detailed history regarding age, sex, types of vehicle, types of victims affected, mode of injury, examination regarding Glasgow Coma Scale (GCS) scores, and associated injuries was prepared, and relevant investigations like computed tomography (CT) scan of head were performed. Data were collected every day by using structured questionnaires. In this way, 14,552 emergency patients were admitted and included in the study.

TBI was classified by GCS scores at presentation as: (i) Mild, with GCS score 13 to 15; (ii) Moderate, with GCS score 9 to 12 , with or without loss of consciousness $>5$ minutes, posttraumatic amnesia $>30$ minutes, or focal neurologic deficit; and (iii) Severe, with GCS score 3 to 8. Patients with mild TBI with normal CT scan findings were discharged after proper initial emergency managements. All the remaining patients with moderate to severe TBI were adequately resuscitated and prepared immediately (some of them) for emergency surgical intervention.

\section{Results}

Over the 3-year study period, 14,552 patients were included in this study, where $72 \%$ were male and remaining $28 \%$ were female (-Fig. 1). The mean age at presentation was 29.9 years (range: 4 months to 75 years). The most common age group was 21 to 30 years with $36 \%(5,239)$ patients followed by $24 \%(3,492)$ patients in 31 to 40 years age group (-Table 1).

All the patients with history of head injury with some neurological findings and CT scan findings were offered admission for observation and management. RTA is the

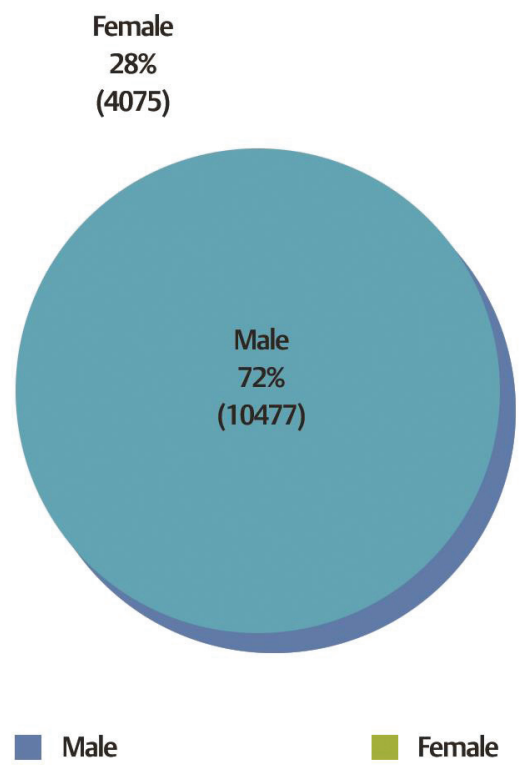

Fig. 1 Gender distribution of study population.

Table 1 Distribution of age $(n=14,552)$

\begin{tabular}{|l|l|}
\hline Age group & Number of patients \\
\hline$\leq 10 \mathrm{y}$ & $2 \%(291)$ \\
\hline $11-20 \mathrm{y}$ & $14 \%(2,038)$ \\
\hline $21-30 \mathrm{y}$ & $36 \%(5,239)$ \\
\hline $31-40 \mathrm{y}$ & $24 \%(3,492)$ \\
\hline $41-50 \mathrm{y}$ & $12 \%(1,746)$ \\
\hline $51-60 \mathrm{y}$ & $8 \%(1,164)$ \\
\hline$\geq 60 \mathrm{y}$ & $4 \%(582)$ \\
\hline
\end{tabular}


Table 2 Etiological pattern of head injury $(n=14,552)$

\begin{tabular}{|l|l|l|l|}
\hline \multicolumn{2}{|l|}{ Etiological pattern } & Frequency \\
\hline Categories & Subcategories & Percentage & Number of patients \\
\hline \multirow{4}{*}{ Road traffic accident } & & 58.3 & 8,483 \\
\cline { 2 - 4 } & Car/bus/truck & 34 & 2,884 \\
\cline { 2 - 4 } & Motor bike & 44 & 3,733 \\
\cline { 2 - 4 } & Train/others & 1.5 & 127 \\
\cline { 2 - 4 } & Pedestrian & 20.5 & 1,739 \\
\hline \multirow{5}{*}{ Fall from height } & & 25 & 3,638 \\
\cline { 2 - 4 } & Roof-top/balcony & 35 & 1,273 \\
\cline { 2 - 4 } & Stairs & 40 & 1,455 \\
\cline { 2 - 4 } & From tree & 18 & 655 \\
\cline { 2 - 4 } & Over vehicle & 7 & 255 \\
\hline Assault & & 15.3 & 2,226 \\
\cline { 2 - 4 } & Blunt & 80 & 1,781 \\
\cline { 2 - 4 } & Sharp & 14 & 312 \\
\cline { 2 - 4 } & Firearm & 6 & 133 \\
\hline Others & & & 204 \\
\hline
\end{tabular}

commonest (58.3\%: 8,483 cases) cause of TBI among which motor bike accidents were in $44 \%(3,733)$ cases, bus/car/ truck accidents were in $34 \%(2,884)$, pedestrian accidents were in $20.5 \%(1,739)$, and accident by train and others were found in only $1.5 \%$ (127) cases. Fall from height scored $25 \%$ $(3,638)$ including fall from stairs in $40 \%(1,455)$, fall from roof-top/balcony in $35 \%(1,233)$, and fall from trees in $18 \%$ (655) cases. TBI following assaults is in $15.3 \%$ (2,226 cases) including blunt assaults in $80 \%(1,781)$ and sharp assaults in 14\% (312) cases (-Table 2 ).

- Figure 2 shows that, among the total admitted patients, $67.94 \%(9,886)$ patients were treated conservatively and remaining $32.06 \%(4,666)$ patients underwent surgical intervention.

Total mild cases were $60 \%(8,731)$, out of which $94.73 \%$ $(8,271)$ cases were treated conservatively and $5.27 \%$ (460) cases underwent surgical intervention. Moderate cases were $25 \%(3,638)$ out of which $36 \%(1.310)$ cases were treated conservatively and $64 \%(2,328)$ cases underwent surgical intervention. Number of severe cases were $15 \%(2,183)$ out of which $14 \%$ (305) cases were treated conservatively and $86 \%(1,878)$ cases underwent surgical intervention (-Table 3, -Fig. 3).

Out of 14,552 admitted patients, $60 \%(8,731)$ patients had mild TBI with GCS score 13 to $15,25 \%(3,638)$ patients had moderate TBI with GCS score 9 to 12 , and remaining 15\% $(2,183)$ had severe TBI with GCS score 3 to 8 at presentation (-Table 4).

On the basis of CT scan of head, diagnoses of TBI were: acute extradural hematoma (AEDH) in 42.3\% $(1,974)$ cases, depressed skull fracture in $28.86 \%(1,347)$ cases, acute subdural hematoma (ASDH) in $12.3 \%$ (573) cases, brain contusion in $10.20 \%$ (476) cases, and subarachnoid

\section{Conservative $\quad$ Surgical intervention}

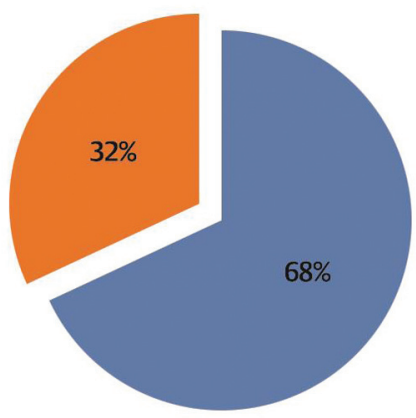

Fig. 2 Distribution of treatment advocated $(n=14,552)$.

hemorrhage (SAH) or combination in $6.34 \%$ (296) cases (-Table 5).

Among the surgical procedures, craniotomy and evacuation for AEDH was done in $42.3 \%(1,974)$ cases, elevation of depressed fragment for depressed skull fracture was done in $28.86 \%(1,347)$ cases, decompressive craniectomy (DC)/craniotomy for ASDH was done in $12.3 \%$ (573) cases, DC/contusectomy for brain contusion was done in $10.2 \%$ (476) cases, and craniotomy/DC for SAH/combined conditions was done in $6.34 \%$ (296) cases (-Table 6).

Discharge was given from 3rd to 7th postadmission day (POD) in conservative patients and between 7th and 15th POD for surgical patients. - Table 7 shows outcomes at 
14 Epidemiology and Treatment Outcomes of Head Injury in Bangladesh Das et al.

Table 3 Distribution of surgical and conservative management based on severity $(n=14,552)$

\begin{tabular}{|l|l|l|l|l|}
\hline \multirow{2}{*}{ Severity } & \multicolumn{2}{|l|}{ Conservative $(\boldsymbol{n}=\mathbf{9 , 8 8 6})$} & \multicolumn{2}{l|}{ Surgical $(\boldsymbol{n}=\mathbf{4 , 6 6 6 )}$} \\
\cline { 2 - 5 } & Number & Percentage & Number & Percentage \\
\hline $\begin{array}{l}\text { Mild } \\
(8,731)\end{array}$ & 8,271 & 94.73 & 460 & 5.27 \\
\hline $\begin{array}{l}\text { Moderate } \\
(3,638)\end{array}$ & 1,310 & 36 & 2,328 & 64 \\
\hline $\begin{array}{l}\text { Severe } \\
(2,183)\end{array}$ & 305 & 14 & 1,878 & 86 \\
\hline $\begin{array}{l}\text { Total }= \\
14,552\end{array}$ & 9,886 & & 4,666 & \\
\hline
\end{tabular}

Mild $\square$ Moderate $\quad$ Severe

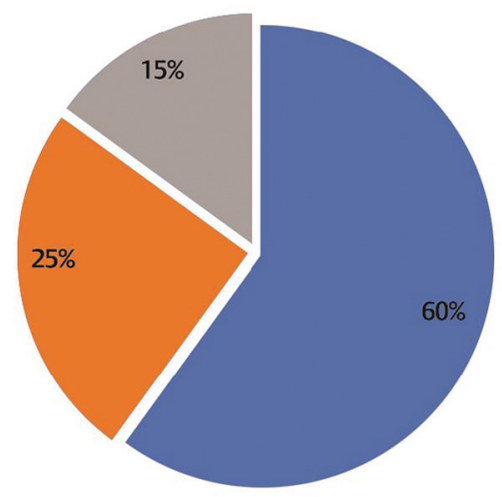

Fig. 3 Distribution of study population based on severity.

Table 4 Types of TBI based on severity $(n=4,666)$

\begin{tabular}{|l|l|l|l|}
\hline \multirow{2}{*}{$\begin{array}{l}\text { Types of TBI } \\
\text { on CT scan }\end{array}$} & \multicolumn{3}{|l|}{ Number of patients } \\
\cline { 2 - 4 } & $\begin{array}{l}\text { Mild } \\
(60 \%)\end{array}$ & $\begin{array}{l}\text { Moderate } \\
(\mathbf{2 5 \% )}\end{array}$ & $\begin{array}{l}\text { Severe } \\
(\mathbf{1 5 \% )}\end{array}$ \\
\hline AEDH & 3,693 & 1,539 & 923 \\
\hline Skull fracture & 2,520 & 1,050 & 630 \\
\hline ASDH & 1,074 & 447 & 269 \\
\hline Brain contusion & 891 & 371 & 223 \\
\hline SAH/combination & 553 & 231 & 138 \\
\hline Total & 8,731 & 3,638 & 2,183 \\
\hline
\end{tabular}

Abbreviations: AEDH, acute extradural hematoma; ASDH, acute subdural hematoma; CT, computed tomography; SAH, subarachnoid hemorrhage; TBI, traumatic brain injury.

discharge by means of Glasgow Outcome Score (GOS). Maximum patients in mild TBI (94.73\%) were treated conservatively and remaining $5.27 \%$ cases underwent surgical intervention due to late deterioration. Almost all of them had favorable outcomes (98\%; GOS 4-5). In case of moderate TBI, favorable outcomes (GOS 5 and 4) were observed in $88 \%$ cases with $10 \%$ unfavorable outcomes
Table 5 Types of TBI based on CT scan findings in surgical group $(n=4,666)$

\begin{tabular}{|l|l|l|}
\hline \multirow{2}{*}{ Types of TBI on CT scan } & \multicolumn{2}{|l|}{ Number of patients } \\
\cline { 2 - 3 } & Percentage & Number \\
\hline AEDH & 42.3 & 1,974 \\
\hline Skull fracture & 28.86 & 1,347 \\
\hline ASDH & 12.3 & 573 \\
\hline Brain contusion & 10.2 & 476 \\
\hline SAH/combination & 6.34 & 296 \\
\hline
\end{tabular}

Abbreviations: AEDH, acute extradural hematoma; ASDH, acute subdural hematoma; $\mathrm{CT}$, computed tomography; $\mathrm{SAH}$, subarachnoid hemorrhage; TBI, traumatic brain injury.

(GOS 2 and 3) with 2\% (46) mortality (GOS 1). In severe TBI, 50\% patients had favorable outcomes (GOS 5 and 4 ) with $50 \%$ unfavorable outcomes (GOS 2 and 3) including 19\% (357) mortality (GOS 1). Mortality was 8.64\% (403) among total surgical interventions $(4,666)$.

- Table 8 shows follow-up at the end of 3 months. We got $60.54 \%(2,581)$ patients for follow-up after 3 months, where $39.46 \%(1,682)$ patients were missing; among them some patients expired and some failed to attend the neurosurgery outpatient department (OPD).

\section{Discussion}

Head injury is considered as a Silent epidemic of the postindustrialization and urbanization era by some authors. ${ }^{19}$ In our study, males in their third and fourth decades of life were the predominant victims of TBI, specially RTA, as they are out for their daily activities and account $\sim 60 \%$ of total victims. Similar observations were reported by the study of Patil et al, ${ }^{19}$ which showed that the people in their most active and productive age group are involved in RTAs, adding a serious economic loss to the community. In this study, it is observed that people aged $<11$ years and $>60$ years are affected by RTAs, which may be due to less activities and less movements of these age groups. Similar findings were observed by some other studies. ${ }^{20-22}$ In our study, male-to-female ratio was found to be 2.57 (72\%):1 (28\%). Another study ${ }^{19}$ shows maleto-female ratio of $4.6: 1$, which does not correlate with our observation probably due to presence of more female workers (i.e., garment workers and day laborers) in our community.

Our study showed that RTA is the commonest (58.3\%: 8,483 cases) cause of TBI among which motor bike accidents were in $44 \%(3,733)$ cases, bus/car/truck accidents were in $34 \%(2,884)$, pedestrian accidents were in $20.5 \%(1,739)$, and accident by train and others were found in only $1.5 \%$ (127) cases, which is similar to the results of the study done by Patil et al. ${ }^{19}$ Motor bike is a very popular, high speed, less stable two-wheeler with less control system used for hurried movements in very busy city traffic area and rural Bangladesh causing maximum of $44 \%(3,733)$ occurrence of the RTA. This may be due to high traffic density, lack of 
Table 6 Types of surgery done based on severity $(n=4,666)$

\begin{tabular}{|l|l|l|l|l|l|}
\hline \multirow{2}{*}{ Name of surgery } & \multirow{2}{*}{ Types of TBI } & \multicolumn{2}{l|}{ Number of patients based on severity } \\
\cline { 3 - 6 } & & Mild (5.27\%) & Moderate (64\%) & Severe (86\%) \\
\hline Craniotomy and evacuation of EDH & AEDH & 195 & 985 & 794 & 1,974 \\
\hline Elevation of depressed fragment & Depressed skull fracture & 133 & 672 & 542 & 1,347 \\
\hline DC/Craniotomy & ASDH & 56 & 286 & 231 & 573 \\
\hline DC/contusectomy & Brain contusion & 47 & 237 & 192 & 476 \\
\hline Craniotomy/DC & SAH/combination & 29 & 148 & 119 & 296 \\
\hline Total & & 460 & 2,329 & 1,878 & 4,666 \\
\hline
\end{tabular}

Abbreviations: AEDH, acute extradural hematoma; ASDH, acute subdural hematoma; DC, decompressive craniectomy; EDH, extradural hematoma; $\mathrm{SAH}$, subarachnoid hemorrhage; TBI, traumatic brain injury.

Table 7 GOS at the time of discharge $(n=14,552)$

\begin{tabular}{|l|l|l|l|}
\hline GOS & $\begin{array}{l}\text { Mild } \\
(\boldsymbol{n}=\mathbf{4 6 0 )}\end{array}$ & $\begin{array}{l}\text { Moderate } \\
(\boldsymbol{n}=\mathbf{2 , 3 2 8 )}\end{array}$ & $\begin{array}{l}\text { Severity } \\
(\boldsymbol{n}=\mathbf{1 , 8 7 8 )}\end{array}$ \\
\hline GOS 5 & $95 \%(437)$ & $72 \%(1,677)$ & $34 \%(638)$ \\
\hline GOS 4 & $3 \%(14)$ & $16 \%(372)$ & $16 \%(300)$ \\
\hline GOS 3 & $2 \%(9)$ & $7 \%(163)$ & $15 \%(282)$ \\
\hline GOS 2 & 0 & $3 \%(70)$ & $16 \%(301)$ \\
\hline GOS 1 & 0 & $2 \%(42)$ & $19 \%(357)$ \\
\hline
\end{tabular}

Abbreviation: GOS, Glasgow Outcome Score.

Table 8 Follow-up GOS of discharged patients after 3 months $(n=4,263)$

\begin{tabular}{|l|l|l|l|l|}
\hline GOS & $\begin{array}{l}\text { Mild } \\
(\boldsymbol{n}=\mathbf{4 6 0})\end{array}$ & $\begin{array}{l}\text { Moderate } \\
(\boldsymbol{n}=\mathbf{2 , 3 2 8})\end{array}$ & $\begin{array}{l}\text { Severity } \\
(\boldsymbol{n}=\mathbf{1 , 8 7 8})\end{array}$ & Total \\
\hline GOS 5 & 352 & 1,050 & 450 & 1,852 \\
\hline GOS 4 & 8 & 241 & 168 & 417 \\
\hline GOS 3 & 4 & 93 & 107 & 204 \\
\hline GOS 2 & 0 & 29 & 79 & 108 \\
\hline Missing & 88 & 730 & 864 & 1,682 \\
\hline
\end{tabular}

Abbreviation: GOS, Glasgow Outcome Score.

traffic rule awareness, and negligence of safety measures (i.e., lack of helmet use).

In case of RTAs by bus/car/truck, the percentage was $34 \%$ $(2,884)$, which may be due to lack of training, traveling without seat-belts, badly shaped roads and vehicles, and alcohol intoxication during driving. Fall from height is another common cause for $25 \%(3,638)$ of TBI cases, especially in children and construction workers. Among fall, varieties of fall included fall from stairs in $40 \%(1,455)$, fall from roof-top/balcony in $35 \%(1,233)$, and fall from trees in $18 \%$ (655) cases. Common victims are children, females, and day laborers due to reasons such as fenceless roof-top working, playing and flying kites, fall from stairs, falling while climbing trees, and fall from electric poles (occupational).

TBI following assaults is also common (15.3\%: 2,226 cases) in our country because of social unrest, relatively easy access to weapons, illiteracy, and poverty. The weapons may be blunt/sharp objects like bamboo, iron rods, Ram Dao, knife, or firearms (e.g., gun shot, blasts). Blunt assaults (80\%: 1,781 cases) are usually associated with comminuted depressed skull fractures while sharp assaults (14\%: 312 cases) are associated with compound depressed fractures; skull fracture itself is considered as an independent risk factor of mortality in severe TBI. ${ }^{23}$

On admission, all TBI patients are categorized on the basis of GCS scores and findings of CT scan and magnetic resonance imaging of the brain in late cases to see detail about brain damage. Among them, mild TBI with GCS score 13 to 15 was in $60 \%(8,731)$, moderate TBI with GCS score 9 to 12 was in $25 \%(3,638)$, and severe TBI with GCS score 3 to 8 was in $15 \%$ $(2,183)$ of the cases. Out of these, $5.27 \%$ of mild cases $(460)$, $64 \%$ of moderate cases $(2,328)$, and $86 \%$ of severe cases $(1,878)$ underwent surgical intervention and remaining $94.73 \%$ of mild cases $(8,271), 36 \%$ of moderate cases $(1,310)$, and $14 \%$ of severe cases (305) were treated conservatively (-Figs. 4-6).

On the basis of CT scan of head, diagnoses of TBI were AEDH in $42.3 \%(1,974)$ cases, depressed skull fracture in $28.86 \%(1,346)$ cases, ASDH in $12.3 \%$ (574) cases, brain
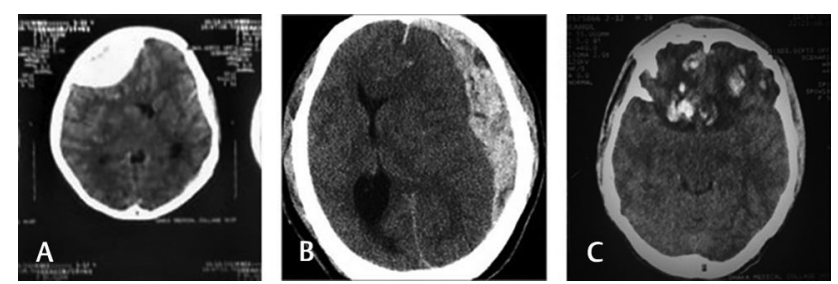

Fig. 4 Varieties of traumatic brain injury: (A) acute extradural hematoma; (B) acute subdural hematoma; (C) bifrontal contusion.
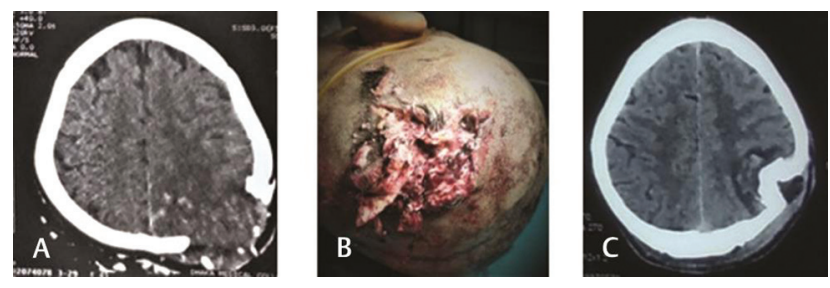

Fig. 5 Varieties of traumatic brain injury (contd.): (A, B) compound comminuted skull fracture with external brain herniation; (C) depressed skull fracture. 


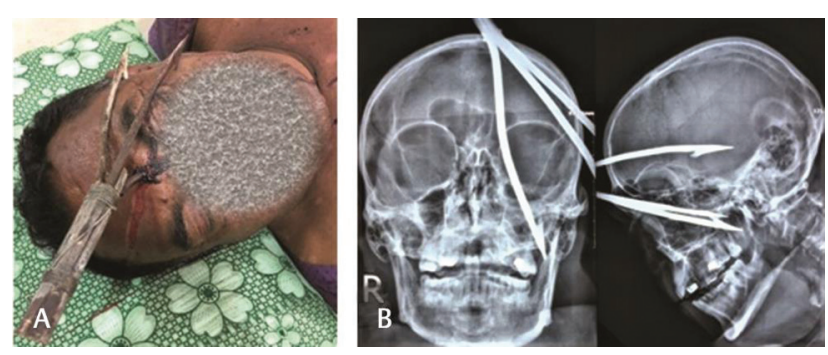

Fig. 6 Varieties of traumatic brain injury (contd.): (A, B) penetrating brain injury (by teta).

contusion in $10.20 \%$ (476) cases, and SAH or combination in $6.34 \%$ (296) cases of the total study population.

Among patients with extradural hematoma, those with clot thickness $\geq 1 \mathrm{~cm}$ or midline shift with deterioration of neurological status are candidates for surgical evacuation. ${ }^{18}$ Patients with depressed skull fractures with neurological findings with risk of further complications are candidates for decompression and/or elevation of depressed fragments. The incidence of ASDH has been estimated as $12.3 \%$ and is directly correlated with preoperative GCS score and time interval between trauma and surgery. ${ }^{6,24-26}$ Patients who had brain contusion (10.2\%) were followed clinically and radiologically. Those who showed increase in size of contusion on repeat CT scan, mild midline shift, or brain becoming very tight with rapid neurological deterioration underwent DC or contusectomy. Penetrating injuries (1\%) are commonly caused by indigenous weapons like teta, sharp weapons, and firearms, which carry a worse prognosis and higher mortality. They are managed with early surgical debridement and prophylactic antibiotics. Removal of foreign bodies from eloquent brain areas reduces the risk of postoperative epilepsy.

Regarding treatment, our study showed that among the total admitted patients, $67.94 \%(9,886)$ patients were treated conservatively and remaining $32.06 \%(4,666)$ patients underwent surgical intervention. Srinivas et $\mathrm{al}^{27}$ show conservative treatment in $20 \%$ cases and surgical treatment in $80 \%$ cases. This study has similarity with our study. Maximum patients in mild TBI (94.73\%) were treated conservatively and remaining $5.27 \%$ cases underwent surgical intervention. All of them $(100 \%)$ had favorable outcomes. In case of moderate TBI, favorable outcomes were observed in $88 \%$ cases with $10 \%$ of unfavorable outcomes including $2 \%$ mortality. In severe $\mathrm{TBI}, 50 \%$ patients had favorable outcomes with $50 \%$ unfavorable outcomes including $19 \%$ mortality. We have $8.64 \%$ mortality in total. Mortality varies with severity of injury. We got $60.54 \%(2,581)$ patients for follow-up after 3 months, where $39.46 \%(1,682)$ patients were missing out of the total 4,263 surgically intervened patients at neurosurgery OPD.

\section{Conclusion}

In etiological pattern, RTA is the commonest cause, where motor bike accident is the commonest and severe most insult among RTAs. AEDH is the commonest type of TBI. Proper training, rapid resuscitation, and immediate definitive management can reduce mortality and morbidity. Proper steps like drivers' training, road maintenance, road visibility and lighting, vehicle fitness checking, rigid traffic rule following, compulsory wearing of crush helmet and seatbelts, road safety education to school children, and strong legislation and law enforcement, all these can reduce RTAs and thereby reduce morbidity and mortality. Roadside trauma center, advanced trauma life support training of service provider, rapid resuscitation facilities, good referral system, and immediate definitive management facilities, all these are also required to reduce morbidity and mortality.

Conflict of Interest

None declared.

\section{References}

1 Roy R, Rahman H, Sultana S, Bhuiyan T. Pattern of injury in RTA patients in Department of Neurosurgery, Rangpur Medical College Hospital. BanglaJ Neurosurg 2019;9(01):22-25

2 Bainbridge J, Khirwadkar H, Hourihan MD. Vomiting-is this a good indication for CT head scans in patients with minor head injury? Br J Radiol 2012;85(1010)183-186

3 Bakir A, Temiz C, Umur S, Aydin V, Torun F. High-velocity gunshot wounds to the head: analysis of 135 patients. Neurol Med Chir (Tokyo) 2005;45(06):281-287, discussion 287

4 Bakshi R. Diffusion-weighted MRI as an evolving standard of care in acute stroke. Neurology 2000;55(10):1595

5 Bell RS, Mossop CM, Dirks MSet al.Early decompressive craniectomy for severe penetrating and closed head injury during wartime. Neurosurg Focus 2010;28(05):E1

6 Bullock MR, Chesnut R, Ghajar J, et al.Surgical Management of Traumatic Brain Injury Author Group. Surgical management of acute subdural hematomas. Neurosurgery 2006;58(Suppl 3): S16-S24, discussion Si-iv

7 Fainardi E, Chieregato A, Antonelli V, Fagioli L, Servadei F. Time course of CT evolution in traumatic subarachnoid haemorrhage: a study of 141 patients. Acta Neurochir (Wien) 2004;146(03): 257-263, discussion 263

8 Tiesman HM, Konda S, Bell JL. The epidemiology of fatal occupational traumatic brain injury in the U.S. Am J Prev Med 2011;41(01):61-67

9 Reeves RH, Beltzman D, Killu K. Implications of traumatic brain injury for survivors of sexual abuse: a preliminary report of findings. Rehabil Psychol 2000;45(02):205-211

10 Maas AI, Menon DK, Lingsma HF, Pineda JA, Sandel ME, Manley GT. Re-orientation of clinical research in traumatic brain injury: report of an international workshop on comparative effectiveness research. J Neurotrauma 2012;29(01):32-46

11 Rutland-Brown W, Langlois JA, Thomas KE, Xi YL. Incidence of traumatic brain injury in the United States, 2003. J Head Trauma Rehabil 2006;21(06):544-548

12 National Center for Injury Prevention and Control (US)Report to Congress on Mild Traumatic Brain Injury in the United States: Steps to Prevent a Serious Public Health Problem. Atlanta: Centers for Disease Control and Prevention2003

13 Menon DK, Schwab K, Wright DW, Maas AIDemographics and Clinical Assessment Working Group of the International and Interagency Initiative toward Common Data Elements for Research on Traumatic Brain Injury and Psychological Health. Position statement: definition of traumatic brain injury. Arch Phys Med Rehabil 2010;91(11):1637-1640

14 Faul M, Xu L, Wald MM, Coronado VG. Traumatic Brain Injury in the United States. Atlanta: Centers for Disease Control and Prevention, National Center for Injury Prevention and Control; 2010 
15 Faul M, Xu L, Wald MM, Coronado VGTraumatic Brain Injury in the United States: Emergency Department Visits, Hospitalizations and Deaths. Atlanta (GA): Centers for Disease Control and Prevention, National Center for Injury Prevention and Control2010

16 Cassidy JD, Carroll LJ, Peloso PMet al.WHO Collaborating Centre Task Force on Mild Traumatic Brain Injury. Incidence, risk factors and prevention of mild traumatic brain injury: results of the WHO Collaborating Centre Task Force on Mild Traumatic Brain Injury. J Rehabil Med 2004;43(Suppl 43):28-60

17 Samandouras GIntroduction to traumatic brain injury. In: Samandouras G, ed. The Neurosurgeon's Handbook. Oxford: Oxford University Press2010:207-208

18 Lee B, Newberg A. Neuroimaging in traumatic brain imaging. NeuroRx 2005;2(02):372-383

19 Patil SS, Kakade RV, Durgawale PM, Kakade SV. Pattern of road traffic injuries: a study from Western Maharashtra. Indian J Community Med 2008;33(01):56-57

20 Jha N, Srinivasa DK, Roy G, Jagdish S. Injury pattern among road traffic accident cases: a study from South India. Indian J Community Med 2003;28:85-90

21 Jooma R, Ahmed S, Zarden AM. Comparison of two surveys of head injured patients presenting during a calendar year to an urban medical centre 32 years apart. J Pak Med Assoc 2005;55(12): 530-532

22 Raja IA, Vohra AH, Ahmed M. Neurotrauma in Pakistan. World J Surg 2001;25(09):1230-1237

23 Tseng WC, Shih HM, Su YC, Chen HW, Hsiao KY, Chen IC. The association between skull bone fractures and outcomes in patients with severe traumatic brain injury. J Trauma 2011;71 (06):1611-1614, discussion 1614

24 Khaled SMCN, Raihan MZ, Chowdhury FH, Ashadullah ATM, Sarkar MH, Hossain SS. Surgical management of traumatic extradural hematoma: experiences with 610 patients and prospective analysis. Indian J Neurotrauma 2008;5(02):75-79

25 Leach P, Childs C, Evans J, Johnston N, Protheroe R, King A. Transfer times for patients with extradural and subdural haematomas to neurosurgery in Greater Manchester. Br J Neurosurg 2007;21(01): $11-15$

26 Tian HL, Chen SW, Xu Tet al.Risk factors related to hospital mortality in patients with isolated traumatic acute subdural haematoma: analysis of 308 patients undergone surgery. Chin Med J (Engl) 2008;121(12):1080-1084

27 Srinivas M, Satish Kumar S, Bola VRet al.Referral pattern to neurosurgeons in a tertiary care teaching hospital. Roman Neurosurg 2018;32(02):377-383 